\title{
Lung carcinosarcoma as a rare biphasic sarcomatoid carcinoma:
} a case report

\author{
Kaushik Sanyal $^{1 *}$ and Kanagasabesan Sabanathan ${ }^{2}$
}

\author{
Addresses: ${ }^{1}$ Department of Rheumatology and General Internal Medicine, Brighton and Sussex University Hospital NHS Trust, UK and \\ ${ }^{2}$ Department of Medicine, Norfolk and Norwich University Hospital, Norwich, UK \\ Email: KS* - ksanyal01@doctors.org.uk; KSab - kamax.sabanathan@nnuh.nhs.uk \\ * Corresponding author
}

Received: 3 December 2008 Accepted: 26 December 2008 Published: 10 June 2009

Cases Journal 2009, 2:7968 doi: 10.4076/1757-1626-2-7968

This article is available from: http://casesjournal.com/casesjournal/article/view/7968

(C) 2009 Sanyal and Sabanathan; licensee Cases Network Ltd.

This is an Open Access article distributed under the terms of the Creative Commons Attribution License (http://creativecommons.org/licenses/by/3.0), which permits unrestricted use, distribution, and reproduction in any medium, provided the original work is properly cited.

\begin{abstract}
Introduction: A fit, 57-year-old man admitted with chest pain and haemoptysis turned out to have a primary tumour in the left lung.

Case presentation: In this 57-year-old Caucasian man, the diagnosis followed a computed tomography scan and histopathological evidence gained post-resection. The biopsy showed a uniform, spindle shape with focal pleomorphism which was suggestive of lung carcinosarcoma.

Conclusions: The authors report this case in literature and discuss how a rare malignant tumour can be found in those presenting with trivial chest symptoms.
\end{abstract}

\section{Introduction}

The description of lung carcinosarcoma was developed in the early $20^{\text {th }}$ century. It is a rare tumour, accounting for $0.3 \%$ of primary lung malignancy. The diagnosis is made through histopathological evidence. The patients presenting with this commonly undergo resection.

\section{Case presentation}

In this report, we present a rare case of a fit, 57-year-old Caucasian man who was admitted with a history of exposure to asbestosis. He presented with chest pain and frank red haemoptysis. For 2-3 weeks he had been complaining of a mild, dry cough and breathlessness on exertion. His other medical history included hypertension, gastritis and migraine. Physical examination revealed decreased air entry in the left upper lobe. The rest of the examination was normal. His chest X-ray (Figure 1) showed a large, mass-like density involving the upper-left and middle zones. Possible differential diagnoses suggested thoracic aneurysm, congenital malformation or carcinoma. A computed tomography scan showed a large, well-defined mass of mixed attenuation occupying most of the upper-left hemi-thorax, stretching mediastinal structures including the left pulmonary artery (Figure 2). There were also background changes of asbestosis. Histological examination showed mainly small, uniform spindle cells but, focally, cellular pleomorphism. There were also focal osseous and chondroid differentiations. The pattern was suggestive of sarcoma.

\section{Discussion and conclusion}

This is a rare malignant tumour which has a mixture of carcinoma and sarcoma consisting of differentiated mesenchymal elements [1]. Regional and distant 


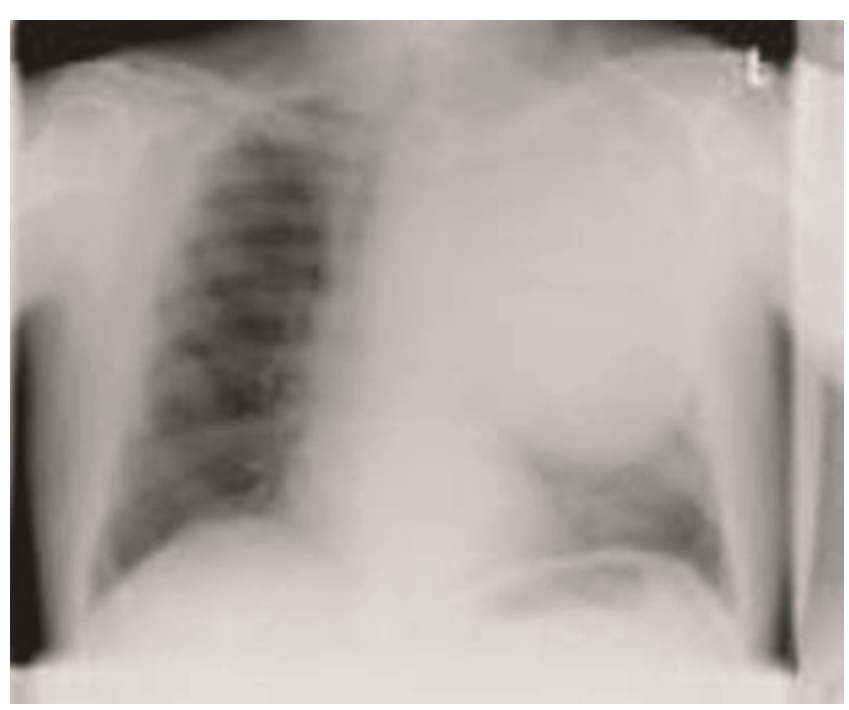

Figure I. Left lung mass.

metastases are infrequent [2]. The peak age for development is in the $5^{\text {th }}$ to the $7^{\text {th }}$ decade of life [3] and there is greater preponderance in men. Final diagnosis is attainable through histological examination combined with the use of different methods, including monoclonal antibody reactions. Expression of cytokeratin and vimentin confirm the diagnosis of the tumour. This usually produces endobronchial irritation and occlusion and the location

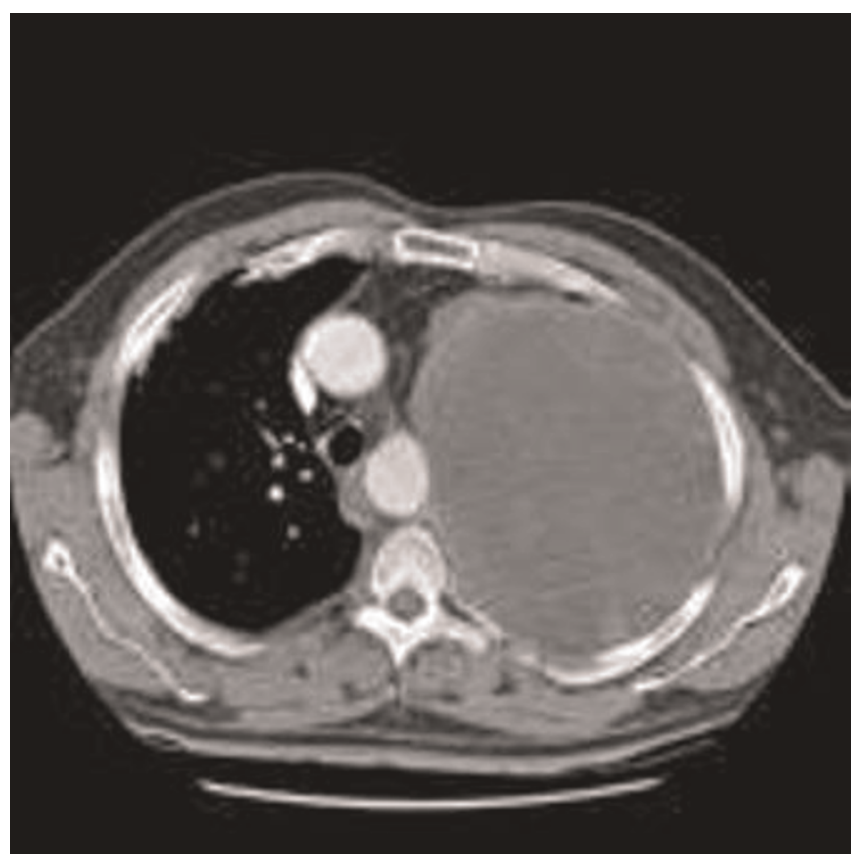

Figure 2. CT scan of carcinosarcoma of the left lung. explains the symptom. Radical tumour resection and postoperative adjuvant chemotherapy are the best treatments.

\section{Review of current literature}

Lung carcinosarcoma is a rare malignancy with a poor prognosis. It accounts for $0.3 \%$ of pulmonary malignancies $[4,5]$ and it is divided into endobronchial (squamous type) and peripheral (glandular type) categories. There are strong associations with smoking and asbestosis. In the endobronchial type, coughing and blood-tinged sputum usually occur; peripheral tumours are asymptomatic. WHO has added the criterion that pulmonary carcinosarcoma should show differentiation of mesenchymal components into specific tissues. Immunohistochemical differential diagnosis of sarcomatoid carcinoma of the airway in the tumour type leiomyosarcoma is: vimentin +ve, leu-7 antigen +ve, collagen type IV +ve, desmin +ve, smooth-muscle actin +ve [6].

For patients with pulmonary carcinosarcoma, the treatment of choice with a clear margin is complete resection [7]. The rate of reversibility ranged from 87-93\% [8]. Adjuvant or neoadjuvant therapy can be considered in selected cases.

\section{Abbreviations \\ None.}

\section{Consent}

Written informed consent was obtained from the patient for publication of this case report and accompanying images. A copy of the written consent is available for review by the Editor-in-Chief of this journal.

\section{Competing interests}

The authors declare that they have no competing interests.

\section{Authors' contributions}

KS interpreted the patient data. KS performed the analysis and a major contributor in writing the manuscript. All authors have read and approved the final manuscript.

\section{References}

I. Koss $M N$, Hochholzer $L$ et al.: Carcinosarcoma of the lung. The American Journal Of Surgical Pathology 1999, 23:I5|4-I526.

2. Jenkins BJ et al.: Carcinosarcoma of the lung. Report of a case and review of the literature. Journal of Thoracic and Cardiovascular Surgery 1968, 55:657-66I.

3. limmermann E, Huwer H, Seitz G: Carcinosarcoma of the lung, a tumour which has a poor prognosis and is extremely rarely diagnosed preoperatively. Thoracic And cardiovascular surgeon 1990, 38:247-250.

4. Carbarcos A, Gomez Dorronsoro M, Lobo Beristain JL: Pulmonary carcinosarcoma: a case study and review of the literature. $\mathrm{Br}$ J Dis Chest 1985, 79:83-86.

5. Ishida T, Tateishi M, Kaneko S: Carcinosarcoma and spindle cell carcinoma of the Lung: clinicopathologic and immunohistochemical studies. J Thorac Cardiovasc Surg 1990, 100:844-852. 
6. Humphrey PA, Scroggs MW, Roggi VL, Shelbourne JD: Pulmonary carcinoma with a sarcomatoid element. Hum Pathol 1988, 19:155-165

7. Petrov DB, Vlassov VI, Kalaydjiev GT, Plochev MA, Obretenov ED, Stanoev VI: Primary pulmonary sarcomas and carcinosarcoma postoperative results and comparative survival Analysis. Eur J Cardiothorac Surg 2003, 23:46I-466.

8. Heremans A, Verbekan E, Deneffe G, Demedts M: Carcinosarcoma of the lung: report of two Cases and review of the literature. Acta Clin Belg 1989, 44:II0-II5.

\section{Do you have a case to share?}

Submit your case report today

- Rapid peer review

- Fast publication

- PubMed indexing

- Inclusion in Cases Database

Any patient, any case, can teach us something

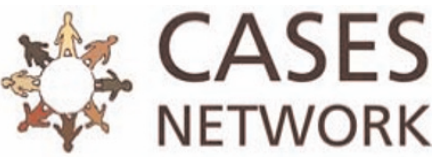

www.casesnetwork.com 